Review

\title{
Fused Deposition Modelling as a Potential Tool for Antimicrobial Dialysis Catheters Manufacturing: New Trends vs. Conventional Approaches
}

\author{
Essyrose Mathew ${ }^{(\mathbb{D}}$, Juan Domínguez-Robles, Eneko Larrañeta *(D) and Dimitrios A. Lamprou *(i) \\ School of Pharmacy, Queen's University Belfast, Belfast BT9 7BL, UK \\ * Correspondence: e.larraneta@qub.ac.uk (E.L.); d.lamprou@qub.ac.uk (D.A.L.); Tel.: +44-28-9097-2360 (E.L.); \\ +44-28-9097-2617 (D.A.L.)
}

Received: 13 July 2019; Accepted: 10 August 2019; Published: 14 August 2019

check for updates

\begin{abstract}
The rising rate of individuals with chronic kidney disease (CKD) and ineffective treatment methods for catheter-associated infections in dialysis patients has led to the need for a novel approach to the manufacturing of catheters. The current process requires moulding, which is time consuming, and coated catheters used currently increase the risk of bacterial resistance, toxicity, and added expense. Three-dimensional (3D) printing has gained a lot of attention in recent years and offers the opportunity to rapidly manufacture catheters, matched to patients through imaging and at a lower cost. Fused deposition modelling (FDM) in particular allows thermoplastic polymers to be printed into the desired devices from a model made using computer aided design (CAD). Limitations to FDM include the small range of thermoplastic polymers that are compatible with this form of printing and the high degradation temperature required for drugs to be extruded with the polymer. Hot-melt extrusion (HME) allows the potential for antimicrobial drugs to be added to the polymer to create catheters with antimicrobial activity, therefore being able to overcome the issue of increased rates of infection. This review will cover the area of dialysis and catheter-related infections, current manufacturing processes of catheters and methods to prevent infection, limitations of current processes of catheter manufacture, future directions into the manufacture of catheters, and how drugs can be incorporated into the polymers to help prevent infection.
\end{abstract}

Keywords: 3D printing; catheters; dialysis; extrusion; infections; manufacturing

\section{Introduction}

In the United Kingdom, there are currently around 30,000 people on dialysis [1]. Over the last 50 years, the provision of chronic dialysis has steadily increased with over 2 million people worldwide being treated with dialysis [2]. Dialysis is a procedure used to remove waste products and excess fluid from the blood when there is decreased kidney function. With over 3000 kidney transplants taking place every year in the United Kingdom and 5000 on the waiting list, Chronic Kidney Disease (CKD) is a pressing issue [3]. The National Health Service (NHS) England estimated spending of approximately $£ 1.45$ billion on CKD in 2009-2010 [4]. CKD is present in about $65 \%$ of people over 85 years of age [5]. CKD is estimated to affect $11-13 \%$ of the population and is forecast to become the fifth leading cause of death worldwide by 2040 [6].

After the age of 18, nephrons in the kidney decline by around 7000 per year. Nephrons cannot be regenerated by the body. Renal blood flow also declines after the age of 40 and there is an increased vascular resistance, so the level of blood that reaches glomeruli for filtration is reduced [5]. Therefore, an aging population may also be a factor in the increasing number of CKD patients as renal function declines with age. The two most common types of dialysis include Haemodialysis (HD) and peritoneal 
dialysis (PD). In HD, by using a central venous catheter (CVC), the catheter is inserted into a large vein usually in the chest. The catheter is made up of two lumens, one in which the blood is taken out of the body and filtered by an external machine. Filtered blood is then returned through the other lumen. In PD, the inside lining of the abdomen is used as a filter, where a catheter is placed in the abdomen, through which fluid is pumped, and as blood passes through vessels lining the peritoneal cavity, waste products and excess fluid are drawn out of blood and into dialysis fluid [7].

There are mainly two types of dialysis catheters (Figure 1A). A tunnelled catheter is one that is tunnelled under the skin to a separate exit site; it is preferred for long-term use due to increased stability with most of the catheter being in the body. Non-tunnelled catheters (NTHCs) are inserted into the body with the majority of the catheter present outside the body. NTHCs are used mainly for temporary vascular access. The type of catheter that is used in patients can also have an effect on the rate of infection. Tunnelled dialysis catheters are often used in patients with end-stage kidney disease and used as a longer-term vascular access route. Tunnelled catheters have a lower risk of infection as they have subcutaneous tunnels that increase the distance between the bloodstream and skin [8]. NTHC is used when urgent vascular access is required and is usually used for short-term vascular access. However, due to an increased risk of complications, NTHCs are the least preferred form of vascular access for chronic HD patients. On a recent study, done on a cohort of 154 patients receiving renal replacement therapy with acute kidney disease, patients with tunnelled dialysis catheters had significantly better delivery of the therapy compared to those with the NTHCs [9]. There was better blood flow and a significantly lower number of complications with tunnelled catheters [10]. A comparable study showed that there was no difference in the first occurrence of infection for tunnelled and NTHCs. However, tunnelled catheters were removed less often [11]. One of the major concerns with the treatment of CKD through HD and PD is the risk of infection.

A

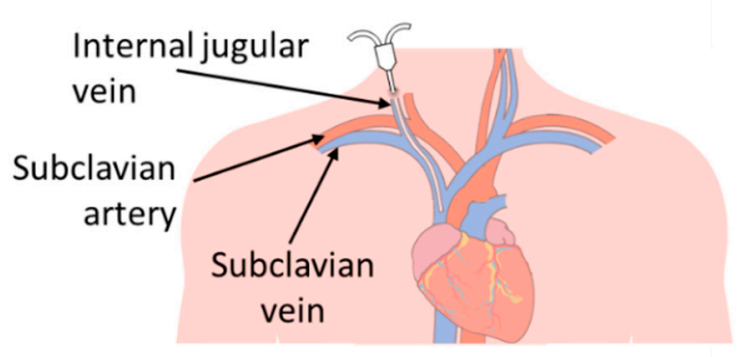

Tunnelled Catheter

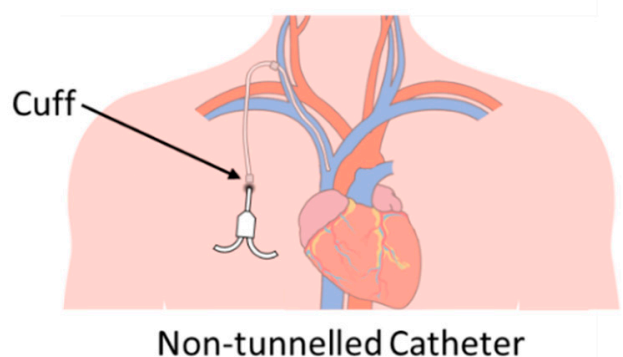

B Right internal jugular vein

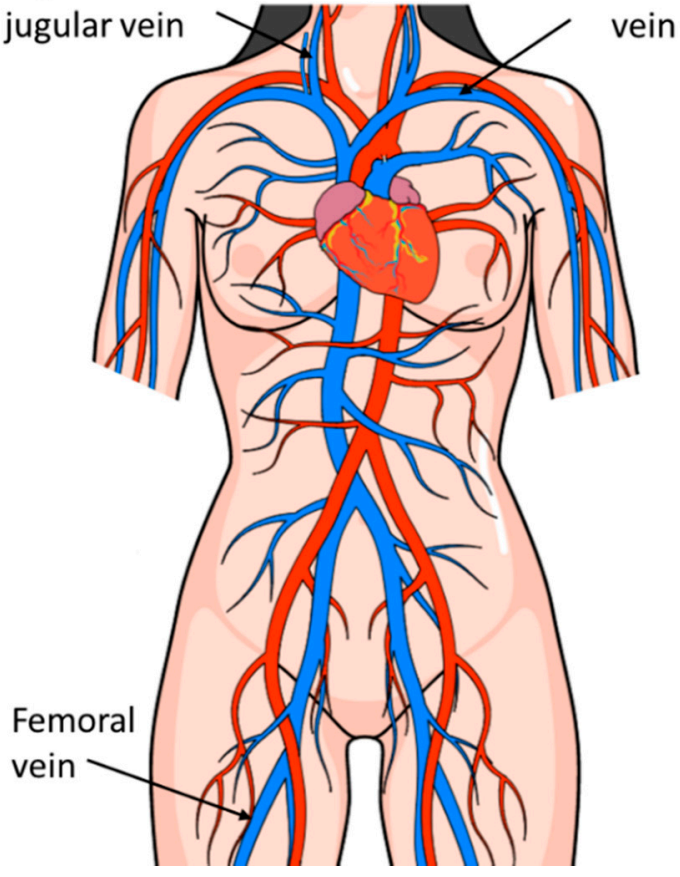

Figure 1. (A) Tunnelled catheter and non-tunnelled catheter. (B) Catheter Insertion sites.

\subsection{Infections}

In patients who undergo dialysis, infections after insertion of the catheter is a prominent issue. Bacteraemia can occur in patients between 0.6 to 6.5 episodes per 1000 catheter days [12] and $87.3 \%$ of catheter-related infections are caused by Gram-positive bacteria, such as Staphylococcus aureus; however, Gram-negative microorganisms, such as Escherichia coli, can also be the cause of bacteraemia 
in patients [13]. Catheter infection complications can occur in $15-40 \%$ of cases. These are most often present in infections caused by S. aureus [14]. In a study done on patients with end-stage kidney disease, $12.8 \%$ of the population developed Staphylococcus aureus bacteraemia (SAB) [15]. There was not a significant difference in the risk of SAB between cuffed and non-cuffed catheters, with the risk being higher in patients with central venous catheters (CVCs) than peritoneal catheters [15].

Bacteria that are antibiotic-resistant, which can increase the difficulty of treatment, often cause catheter-associated infections. The cost to the NHS in the United Kingdom of methicillin-resistant Staphylococcus aureus (MRSA) in HD patients is estimated at $£ 1.4$ million [4]. According to the same report, annual costs per patient are $£ 24,043$ for HD and $£ 20,078$ for PD.

The risk of infection can also rise according to the position in which the catheter is inserted. The risk of infection is higher for the subclavian site (chest) of insertion and lower for femoral (groin) and jugular (neck) (Figure 1B). Insertion success is also significantly higher for femoral and jugular sites compared to subclavian [16]. However, a controversial study has stated that there is no statistically significant relationship between infection and insertion site of the device [17].

Around $64 \%$ of hospital-acquired infections are caused by viable bacteria attaching to medical devices and implants [18]. Catheter-related infections are typically distinguished from colonisation-tip culture yielding $>103$ CFU [19]. Therefore, it is important to find a solution that prevents bacteria from attaching to the surface of medical devices, such as catheters with antimicrobial properties that prevent bacteria from being able to proliferate. Biofilm formation is characteristic of around $80 \%$ of all human infection. Bacterial biofilms are protected by a matrix of polymeric substances on their surface and enable multidrug resistance to occur within these matrices [20]. Figure 2A shows an example of a peritoneal dialysis catheter-related infection. A factor that contributes to the high risk of infection in dialysis patients is fibrin sheath formation (Figure 2B).
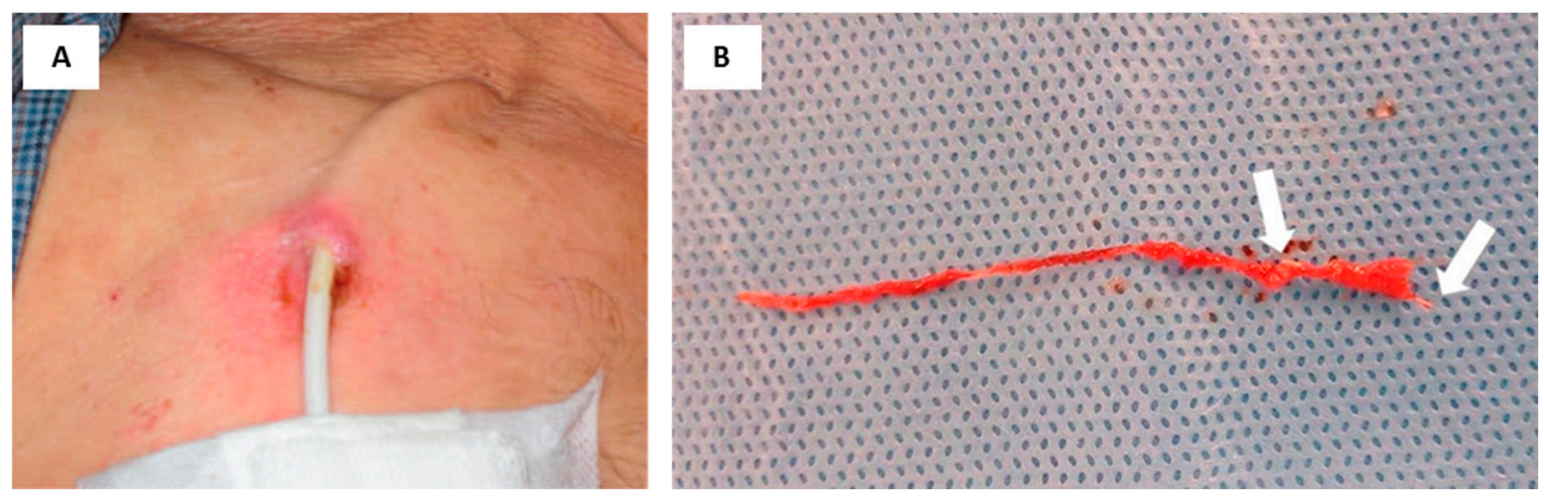

Figure 2. (A) Example of peritoneal dialysis catheter exit site infection. (B) Fibrin sheath formation was detected around the tip of the removed catheter (arrow). Reproduced with permission from: Lok et al. [21] and Mogi et al. [22]. Copyright 2018 Elsevier.

\subsection{Fibrin Sheath Formation}

Fibrin sheath formation is a complication that occurs with HD catheters. It is common in cases of late catheter dysfunction [23]. A fibrin sleeve can form around the catheter, which can affect the function of the catheter and cause ineffective HD. Fibrin sheath formations can occur from 14 days of catheter insertion, according to animal studies [24]. At the earlier stages of fibrin formation, the sheath may be non-occlusive but can cause occlusions at later stages [25]. One method that has been used to prevent fibrin sheath formation is the use of water-infused surface protection (WISP) on CVCs. WISP creates a boundary layer on the inner lumen of CVCs, so that blood does not come into contact with the lumen walls. This method showed a significant reduction in the surface density of adhering proteins and therefore had a negative effect on fibrin sheath formation [12]. May et al. has also shown the addition of Sharklet micropatterns onto the surface of the catheter to have $86 \%$ and $80 \%$ reduction in 
platelet adhesion and fibrin sheath formation, respectively. In addition to the reduction in fibrin sheath formation, this method also reduced bacterial adhesion of S. aureus and Staphylococcus epidermidis [26].

\section{Current Processes}

Current processes for the manufacture of catheters require moulding. Molten polymer is poured into a rubber mould and cured. The curing process is time consuming, as the heat needs to flow from outside the catheters through the entire body by thermal conduction or by infrared radiation (IR) [27]. Injection moulding has also been used for the manufacture of catheters, and is the process by which molten polymer is injected into a mould [27].

Catheters are made with silicone, polyurethane (PU), or latex. Latex allergy is common among individuals so pre-manufactured catheters may create added complications to patient treatment if allergy occurs. A study done on ventricular catheters by Weisenberg et al. stated that ventricular catheters currently are made from a silicone material and are available as straight tubes, which can then be cut appropriately for the dedicated use, in angular configurations or a set length [28]. Thermoplastic elastomers are often used due to their elasticity, which allows the catheters to be inserted with more ease and lower risk of damaging blood vessels. Due to inertness in the body, flexible properties, and blood compatibility, PU has been identified as a good polymer for use in medical devices [29].

Rough edges can encourage bacterial adhesion as well as increased risk of damage to vessels; therefore, smooth surfaces on catheters are preferred. Hydrophilic coatings are sometimes used on catheters as they provide more lubrication, so a lower insertion force is required and there will be lower friction on insertion. A method used currently to help prevent infection occurring in patients with dialysis catheters is the use of coatings around the catheters.

\subsection{Catheter Coatings}

Coatings are used in catheter manufacturing to support the reduction of infection. These coatings can consist of antimicrobial agents that can help prevent adherence of bacteria onto the surface of catheters. Although coatings have been proven to prevent adherence of bacteria in most cases, coatings have some limitations. Currently depending on the type of coating, a concentration of $2 \%$ $(w / w)$ is needed for an antimicrobial effect, whereas a study with 3D-printed catheter tips has shown antimicrobial properties present from as little as $1 \%(w / w)$ [30].

\subsubsection{Pyrogallol Coating}

Pyrogallol (PG) coating on a catheter works effectively against $S$. aureus, but much higher concentrations are required in order to work effectively against $E$. coli. However, as these are some of the most common pathogens causing catheter-related infections, it is important to use an antimicrobial agent that is effective against a wide range of pathogens [17]. PG-coated catheters are dependent on concentration for an antimicrobial effect, with a concentration of $125 \mu \mathrm{g} / \mathrm{mL}$ required to have an antimicrobial effect against both S. aureus and E. coli [31]. PG can be used as an antibiotic free coating and so reduce the potential for antibiotic resistance to occur. Balne et al. used PG- and metal ion-coated catheters with the coating having similar properties to the non-coated catheter with added wettability [31]. The coated catheters also showed significant activity against MRSA strains, which are common bacterial strains associated with catheter infection. PG was tested at concentrations of $0.1 \%$, $1 \%$, and $2 \%(w / v)$, with higher concentrations having a greater zone of inhibition. The antimicrobial properties of PG and PG with antimicrobial metal ions were proven to have broad-spectrum activity [31].

\subsubsection{Heparin Coating}

Heparin-coated catheters have been shown to decrease fibrin deposits that may increase biofilm formation and are the form of catheter used currently in hospitals to minimise infection. Antimicrobial coated catheters are associated with a lower rate of colonisation and catheter-related infection [19]. Animal studies have shown a decreased rate in thrombus formation with heparin-coated catheters. 
As HD catheters may remain inserted for several months, heparin has the potential to cause adverse effects [32]. As heparin is an anticoagulant, it can cause bleeding, allergic reactions, and increase the risk of osteoporosis with long-term use. However, it is often used in heparin-bonded catheters to prolong the usefulness of a catheter [33]. Heparin-induced thrombocytopenia (HIT) can occur when patients are exposed to any level of heparin [34]. However, in a study on 130,000 patients with heparin-bonded grafts, the incidence rate of HIT was $<0.1 \%$. This is because HIT occurs after systematic administration of heparin. Therefore, in the case of intravenous catheters, there would be a higher risk of developing HIT and so it is a greater cause for concern when administering HD and PD catheters [35].

\subsubsection{Silver Particles}

Silver particles have antimicrobial activity against both Gram-positive and Gram-negative bacteria. Additionally, this material shows low cytotoxicity. Therefore, silver particles have the potential to be included in catheter coatings [36]. Figure 3 shows a schematic representation of the known mechanisms of antibacterial action of silver nanoparticles, which are: (1) The silver nanoparticles adhere to the bacterial surface; (2) DNA within the bacterial cell is damaged due to the silver nanoparticles; (3) $\mathrm{Ag}^{+}$ions are released, which have antimicrobial properties. These ions interact with the proteins in the bacterial cell wall, causing the cell wall to lose functionality; (4) $\mathrm{Ag}^{+}$ions disrupt the proton electrochemical gradient in bacteria, resulting in reduced ATP synthesis, which can lead to cell death.

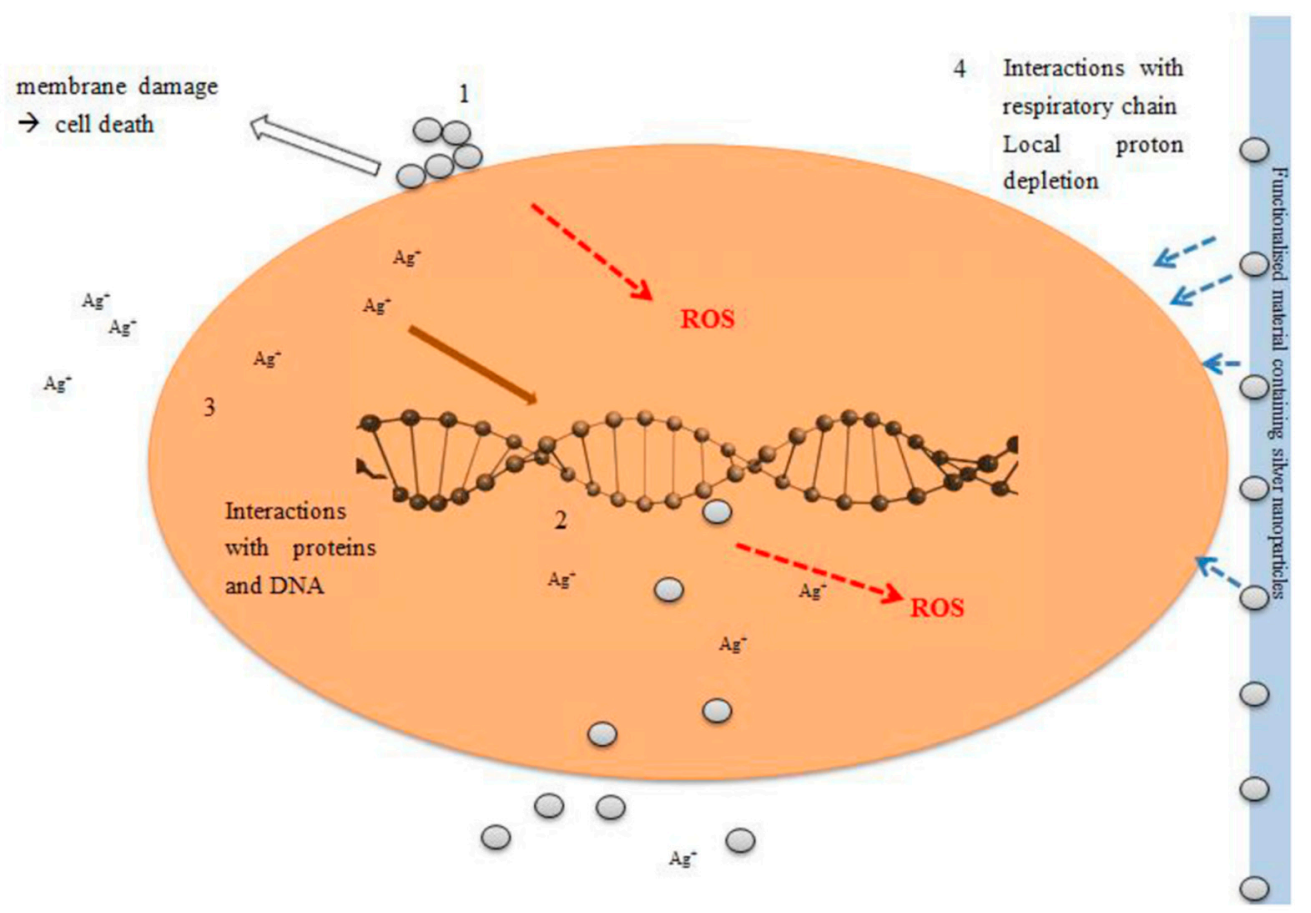

Figure 3. Schematic representation of the known mechanism(s) of antibacterial action of silver nanoparticles and released ionic silver. The numbers 1-4 correspond to the mechanisms described in the paragraphs above. Grey circles indicate silver nanoparticles (NPs) and $\mathrm{Ag}^{+}$implies ionic silver released from the NPs. Reproduced with permission from Reidy et al. [37].

The antimicrobial activity is dependent on the dose of silver nanoparticles [38]. Nonetheless, higher doses have been associated with increased cytotoxicity [38]. Interestingly, Kuehl et al. showed that silver coatings had limited activity against $S$. aureus with combination therapy of silver alongside an antibiotic such as vancomycin, producing greater activity against MRSA [39].

Freitas et al. used the sol-gel method for deposition of titanium onto the surface of central venous catheters, followed by the addition of silver particles by irradiation. The results showed that this method did not produce a homogenous coating on the catheters. Further antimicrobials tests also 
showed that these catheters did not have antimicrobial activity [40]. Additionally, a meta-analysis showed that silver impregnated catheters, which have been used to reduce the risk of infection, were not associated with reduced rates of bacterial colonization or catheter-related bloodstream infections [41]. Therefore, there are still some questions around whether silver nanoparticles have significant antimicrobial activity when incorporated into coatings. Although there are many articles showing the antimicrobial activity of silver nanoparticles, not all of these are tested in vivo [39,40,42]. Additionally, microorganisms vary in their sensitivity to silver [43]. A recent study showed that silver nanoparticles had antimicrobial activity against E. coli, Klebsiella pneumonia, Acinetobacter sp., and Pseudomonas aeruginosa at concentrations of $0.5-2.5 \mu \mathrm{g} / \mu \mathrm{L}$. However, there was no significant activity against $S$. aureus, i.e., a Gram-positive bacterium, and, as discussed above, infections are most commonly caused by Gram-positive bacteria [42]. Another recent work also confirmed that silver nanoparticles were less effective in S. aureus than in E. coli [44]. This may be due to the presence of the thicker peptidoglycan layer in Gram-positive bacteria, which may provide some added protection to the bacteria in comparison to Gram-negative bacteria [45]. Various studies have also shown that there is a cause for concern with the increased use of silver nanoparticles in medical devices, as silver resistance strains of bacteria may form [46-48]. Silver nanoparticles have also been shown to create histopathologic abnormalities in the liver, spleen, and lung, as well as toxicity in the muscle. However, there are few studies on the potential toxicities of silver nanoparticles and range of doses that may cause toxicity [49]. Due to these limitations, silver particles are not frequently used in current catheter coating processes.

\subsection{Limitations of Coated Catheters}

There are limitations to the use of coated catheters. If used over a long period, there is potential for the antimicrobial agent to cause toxicity [32]. A large amount of antimicrobial agent is also required to have a significant antimicrobial effect. The volume of antimicrobial agent required to coat catheters before providing a significant antimicrobial effect is high in comparison to additive manufacturing (AM) techniques.

A major problem with coated catheters is the development of resistance to antimicrobials with catheter-associated infections [31]. Over time, as the antimicrobial agent is released from the coating, the coating becomes thinner, resulting in a lower rate of release of drug. This change in rate of release can increase the potential for antibiotic resistance. Slow drug release from catheter coatings presents the issue of finding the balance between a sufficient amount of drugs in the coating for antimicrobial effect and limiting the coating thickness to ensure physical properties of the catheter remain [50].

Catheter coating also requires the modification of both the inner and outer surfaces of the catheter for optimal effect against bacteria, which lengthens the manufacturing process. Bacterial growth on the inner surface of catheters also requires a higher concentration of antibiotics to stop growth than on the outer surface [51].

It is important to note that the current manufacturing process is generic and is not adapted to the patient's needs. Moreover, it is expensive to create drug-coated polymers as well as there being an increased wastage of material during the coating process. Due to these limitations, it is obvious that there is a need to develop new technologies for catheter manufacture.

\section{Future Directions for Catheter Manufacture: Challenges and Expected Impact}

\subsection{Additive Manufacturing}

One of the novel technologies of AM includes 3D printing. This technique is a process in which a digital file made using computer-aided design (CAD) can be printed into a physical object. This allows for a representation of the model to be created using computer software before its final release, which reduces the time for developmental stages of manufacture [52]. As the pharmaceutical and medical devices industries are moving towards personalized medicine and medical devices, the future direction 
of AM will enable the use of imaging of patients, to design patient-matched devices through computer modelling software and 3D print these devices. 3D Printing is an AM technique in which polymers can be extruded and deposited in multiple layers to create an object. Fused deposition modelling (FDM), to the best of our knowledge, is the only AM technology with published data in the area of catheters and with a promising future in this area. However, use of other 3D printing technologies (e.g., Selective laser sintering (SLS)) might be possible in the near future. The three main principles through which FDM works is the extrusion of polymer, depositing material in successive layers, and cooling of material on the printer bed to solidify structure.

FDM could be used in the manufacturing of catheters, allowing flexibility in the choice of polymer-used design specifications, according to the patient. Table 1 outlines the advantages and disadvantages of FDM.

Table 1. Table summarising advantages and disadvantages of fused deposition modelling.

\begin{tabular}{cc}
\hline Advantages & Disadvantages \\
\hline Rapid Manufacture & Drug needs to have similar or higher melting point to polymer \\
Less expensive & Small range of thermoplastic polymers \\
On-demand Fabrication & Lower resolution than stereolithography \\
Patient Matched Device & Difficult to produce small diameter filament \\
\hline
\end{tabular}

Risk of infection would persist; therefore, antimicrobial properties are required to reduce infection rates. FDM allows the potentials of antimicrobial filaments to be used in which the polymer has an antimicrobial drug mixed-in. One way in which antimicrobial filaments can be created is through hot-melt extrusion (HME).

The use of additive manufacturing for catheter preparation has been barely described in the literature. There are two papers describing the use of this technology for catheter preparation [30,53]. These basic studies are proof of concept studies and accordingly contain many aspects that should be improved before this technology can be applied to patients. The catheters described in this study are prepared using poly(lactic acid) (PLA), methotrexate, and gentamicin (Figure 4). PLA is not the most appropriate candidate for catheter manufacturing for several reasons that will be discussed further below. Moreover, the resulting catheters showed high surface roughness (Figure 4A,B). This factor should be improved as surface irregularities promote bacterial adhesion and biofilm accumulation [54]. However, there are simple ways to reduce surface roughness for FDM-produced devices $[55,56]$. Finally, the resulting catheters showed gentamicin release over a period of up to five days. However, the authors did not check if the catheters retained its antimicrobial activity after five days. This is another important point that needs to be considered for future works.
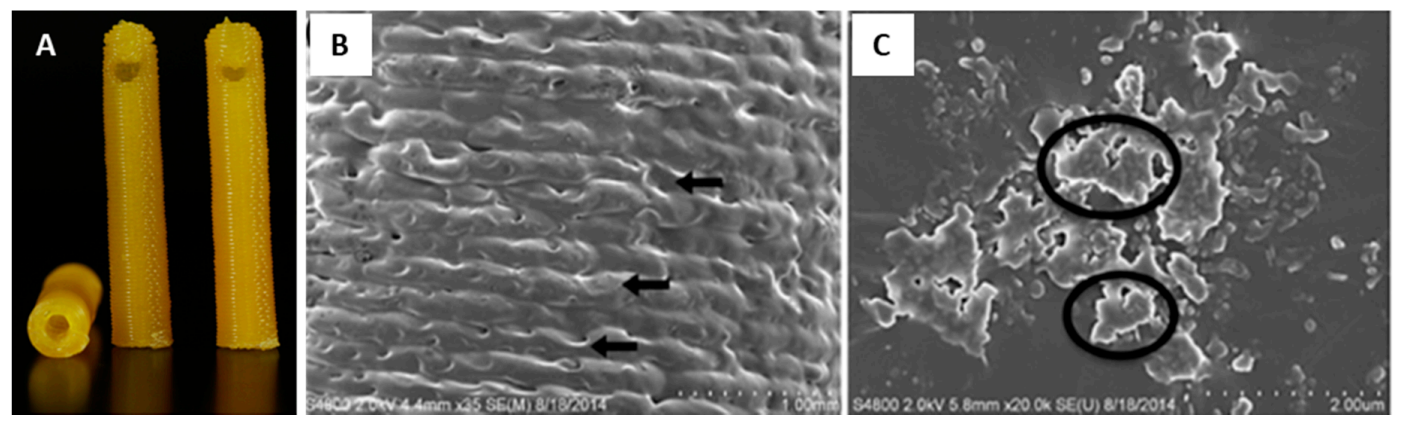

Figure 4. Photograph of the methotrexate-laden three-dimensional (3D)-printed catheter (A). Scanning electron microscope images of gentamicin-laden 3D-printed catheters (B,C). Multiple amorphous defects seen at $35 \times$ magnification suggest gentamicin incorporation into the catheter structure (B, arrows). This is confirmed at 20,000 $\times$ magnification, which highlights the amorphous configuration of gentamicin (C, circles). Reproduced with permission from Weisman et al. [30]. Copyright 2019 Elsevier. 


\subsection{Hot-Melt Extrusion}

HME is a process in which heat and pressure are applied to create molten material and force it through an orifice to create uniform filaments. Figure 5 shows a medical tubing extrusion line. Traditional methods such as spray drying (spraying equipment, such as spraying drying, is also being used for coating stents and catheters) involve the use of organic solvents, creating disposal and environmental issues. As HME is a solvent-free process, it is a preferred method due to the reduced waste of organic solvent and its environmentally friendly nature [57]. It is a process in which an active drug can be processed with a polymer as a carrier [58]. A recent study done on wound dressings made from polymer extrudates with antimicrobial metal ions showed the potential for creating patient-specific devices with HME materials [59]. HME extrusion has been used to create filaments for FDM 3D printing. A study by Melocchi et al. uses HME to produce filaments using ethyl cellulose (Eudragit RL), polye(thylene oxide) (PEO), and poly(vinyl alcohol) (PVOH), which were then successfully 3D printed into discs using an FDM printer [52]. HME has also been used to improve the compatibility of certain polymers for FDM printing. For example, pure Eudragit is too brittle to be printed; however, when combined with a plasticizer using HME, filaments are produced with more desirable properties for FDM printing [60]. Alhijjaj et al. also explored the creating altered drug release rates from FDM-printed objects by altering the polymer blends through HME. PEG, PEO, and Tween 80 with Eudragit or Soluplus were studied, as well as blends with PVA, which is commonly used in FDM printing [61]. This method of HME can be used to combine a wide range of polymers to produce filaments with differing mechanical properties to suit the application [62].

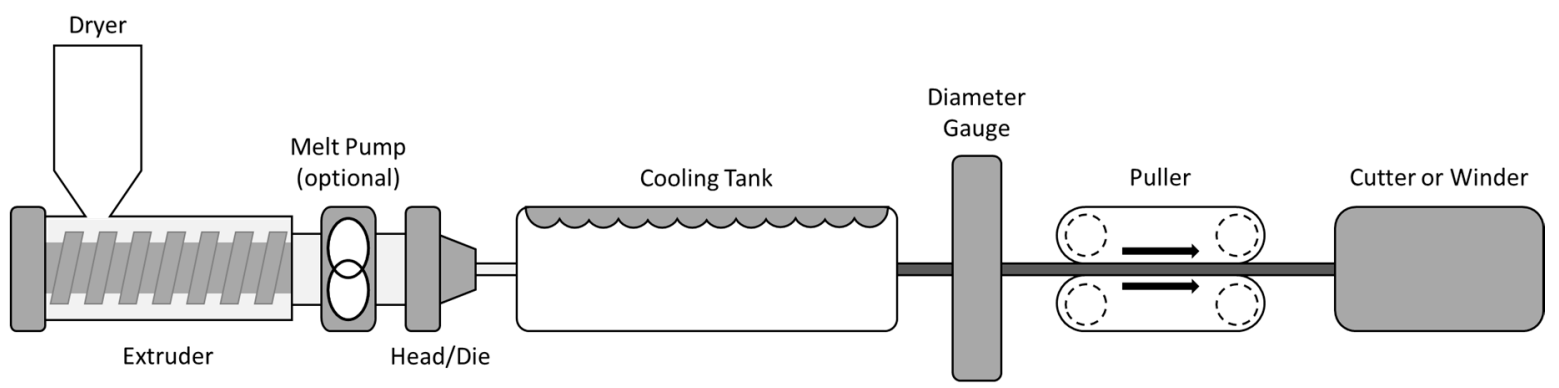

Figure 5. Typical medical tubing extrusion line. This type of extrusion line contains several pieces of equipment, including a drying system, an extruder, a die, a cooling tank, a take-up device (puller), and a winder or cutter.

\section{Suitable Materials for Additive Manufacturing}

As described above, there are not many reports on the use of AM for catheter manufacturing. However, this promising technology can be a good alternative to prepare medical materials on demand, including catheters. Several materials can be used for this purpose. These materials are mainly polymers that have been used before for $3 \mathrm{D}$ printing applications and have been proven to be biocompatible.

\subsection{Poly(Lactic Acid)}

Poly(lactic acid) (PLA) (Figure 6) is a polymer that is biodegradable and bioresorbable [63,64]. PLA is an inexpensive polymer and easily accessible, that melts in the range of $180-220^{\circ} \mathrm{C}$, making it a suitable polymer for 3D printing. The products of degradation from PLA are easily excreted out of the body by kidneys and products of degradation are non-toxic to the body [65]. Considering that renal function is compromised in CKD patients, the use of biodegradable polymers is not ideal. Moreover, the surface of the catheter will be eroded over time. Accordingly, these types of catheters will not be recommended for prolonged use. Moreover, as PLA can be hydrolysed, it is important to consider the storage of PLA in humid environments as the moisture from the air could hydrolyse the polymer [66]. In biomedical applications, PLA has been used for tissue engineering, sutures, and prostheses [67]. 
PLA is also generally recognised as a safe material by the food and drug administration (FDA) [68]. Potential drawbacks of PLA include its poor thermal stability and brittleness, which make it less favourable for large-scale manufacturing. However, it is a popular material used in AM and has been proven to be effective in FDM [56]. A study on microfluidic devices has shown the use of PLA through FDM to manufacture medical devices, with less than $1 \%$ variability shown between replicate prints [69]. PLA stents have also been produced through FDM, with a printing temperature of $220^{\circ} \mathrm{C}$ [70]. This shows that PLA can be successfully used in the process of FDM. PLA has also been proven for its uses within HME, with studies showing the manufacture of dexamethasone implants for the controlled release of immunosuppressive and anti-inflammatory drugs [71,72]. Moreover, PLA has been recently used to manufacture 3D-printed catheters containing a chemotherapeutic agent (methotrexate) or an antibiotic (gentamicin sulphate) to be used as a type of personalized medicine in interventional radiology [30].

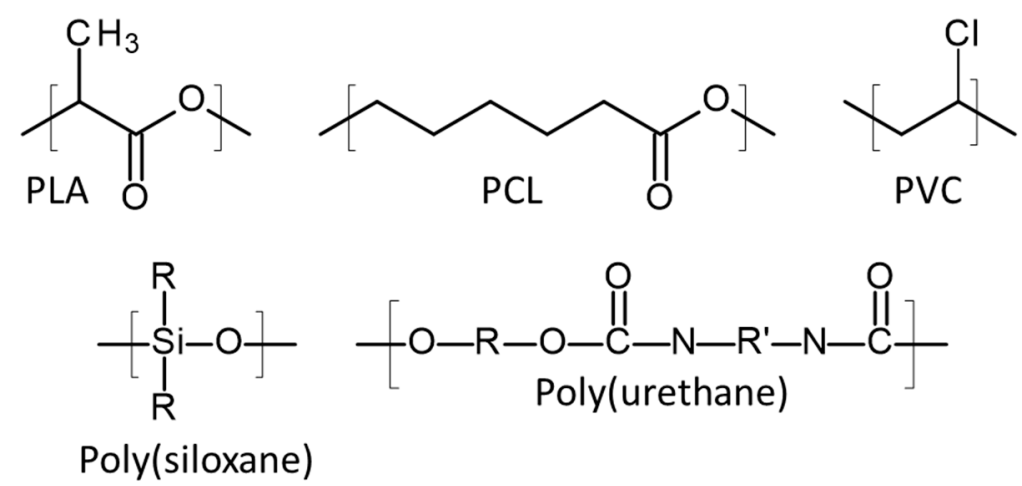

Figure 6. Chemical structures of poly(lactic acid) (PLA), poly(caprolactone) (PCL), poly(vinyl chloride) (PVC), poly(siloxane), and poly(urethane).

\subsection{Poly(Caprolactone)}

Poly(caprolactone) (PCL) (Figure 6) has a low melting point of ca. $60{ }^{\circ} \mathrm{C}$, which is good for extrusion [63]. PCL is biodegradable and thermally stable so it can withstand the high temperatures used in FDM and HME. PCL also has a low glass transition temperature at $-60{ }^{\circ} \mathrm{C}$, making it a more flexible material [73], and has been used to print stents through FDM effectively at a temperature of $220{ }^{\circ} \mathrm{C}$ [70]. The stents produced achieved $85-90 \%$ accuracy through the FDM printing process. Additionally, Fu et al. produced a progesterone-loaded filament through $\mathrm{HME}$ at $190^{\circ} \mathrm{C}$, which was then printed into vaginal rings using FDM at a printing temperature of $195^{\circ} \mathrm{C}$ [74].

\subsection{Poly(Vinyl Chloride)}

Poly(vinyl chloride) (PVC) (Figure 6) is a thermoplastic material with a melting point of around $240{ }^{\circ} \mathrm{C}$. When PVC is plasticised, it can have some advantageous properties, such as good biocompatibility, flexibility, and strength, and has been used in biomedical applications for catheters, gloves, and blood bags [75]. Sharma et al. has shown the effective extrusion of PVC granules into filaments, and further processed the PVC filaments through FDM [76]. This study also tested the mechanical properties of the PVC-printed constructs, highlighting the potential use in HME and FDM. The first plastic catheter manufactured in 1945 using PVC and PU, but nowadays, these catheters are in disuse due to their rigidity/stiffness, thrombogenic capacity, and for causing bacterial adherence. In general, plasticisers can leach from the polymer matrix, as they are not covalently bonded to the polymer. There is also a risk of drugs in the body migrating into plastics, which could lead to drugs falling below the therapeutic threshold [77]. 


\subsection{Thermoplastic Poly(Urethane)}

Polyurethanes (PU) are a family of polymers that are widely used in the manufacture of biomedical devices (Figure 6). Thermoplastic polyurethane (TPU) is a polymer commonly used in the manufacture of catheters with a melting point of around $200^{\circ} \mathrm{C}$. They are popular in the manufacture of catheters for dialysis as well as urinary catheters, due to their flexibility, good blood compatibility, and strength. In fact, the incidence of catheter-related bloodstream infection is lower for PU catheters than those made of PVC or PU and so it is the current material of choice in manufacturing of catheters, particularly due to its potential to form sustained release polymers through HME, which has been proven in medical tubing [78]. One study in particular outlines the use of TPU in HME and its potential for use in FDM printing [79]. To conclude, TPU filament is suitable for 3D printing and has potential for creating customised and repeatable products.

\subsection{Silicone}

Silicone, is an inert polymer with good thermal stability, moisture resistance, and flexibility [80]. An alternative name for this type of polymer is poly(siloxane) (Figure 6). Silicone has a glass transition at around $-127^{\circ} \mathrm{C}$ and a melting point at around $-43^{\circ} \mathrm{C}$ [81]. It is resistant to temperature from -55 to around $300^{\circ} \mathrm{C}$. Silicone has been extensively used for the production of catheters; for example, on the production of antimicrobial graphene nanoplatelet coatings for silicone catheters, and on the surface modification of silicone with colloidal polysaccharide formulations for the development of antimicrobial urethral catheters. Silicone has been proven to have effective use in FDM printing $[82,83]$. There was a study done to show the effective use of moisture-cured silicone in extrusion based AM [82]. It also has minimal leaching of plasticisers from its matrix.

\subsection{Latex}

Latex is used in the manufacture of catheters, as it is a soft flexible material with a melting point of around $180^{\circ} \mathrm{C}$. Latex has a high stretch ratio, is impermeable to water, and is a resilient material [84]. This is the original material used in the manufacture of Foley urinary catheters. An issue with latex catheters is cytotoxicity, due to elute from the rubber. Therefore, latex is not as commonly used today as PU or silicone catheters. Some latex catheters may be covered with a layer of silicone in order to minimise cytotoxicity. However, as latex is a rubber, it is not ideal for the processes of HME and FDM. Once latex becomes molten and sets, it cannot be melted again. Therefore, latex is not considered as a thermoplastic elastomer.

\section{Regulatory Considerations on 3D-Printed Medical Devices}

Since the FDA first approved a 3D-printed drug (Spritam ${ }^{\circledR}$, Aprecia Pharmaceuticals, Blue Ash, OH, USA) in 2015, there has been a growing interest in 3D printing of pharmaceutical products and devices. This has also provided a major breakthrough in the regulation of 3D-printed pharmaceuticals [85]. 3D printing offers the potential to produce multiple devices daily using one process with flexibility within the device design process. However, this also opens up the opportunity for variability to occur [86]. Therefore, the FDA have released guidance documentation on AM of medical devices. The guidance focuses around design and manufacturing considerations and device testing considerations for 3D-printed medical devices. The guidance covers areas such as file format conversions, validating and automating software processes, material controls, device testing considerations, and material characterisation. As the potential to create patient-matched devices is a major advantage of AM, the FDA states that when imaging a patient, a risk-based approach should be used to assess scenarios in which a worst-case match to the patient would be produced. Quality must be maintained for all devices by performing process validation for all devices and components built in a single build cycle, between build cycles, and between machines. For all validated processes, there should be clear documentation on the data and monitoring and control methods. Revalidation must be performed 
when there have been any changes made to the manufacturing process to assess any risks the changes may bring. Throughout the documentation, there are also references to current guidance that already exists for medical devices; therefore, the guidance provided on AM should be supplemented with existing guidance on a particular medical device [87].

Author Contributions: Conceptualization, E.M., J.D.-R., E.L. and D.A.L.; Investigation, E.M., J.D.-R. and E.L.; Writing-original draft preparation, E.M., J.D.-R. and E.L.; Writing-review and editing, J.D.-R., E.L. and D.A.L.; Supervision, E.L. and D.A.L.

Funding: This research received no external funding.

Conflicts of Interest: The authors declare no conflict of interest.

\section{References}

1. Kidney Care UK. Patient Reported Experience of Kidney Care in England and Wales 2017; Kidney Care UK: Alton, UK, 2017.

2. Couser, W.G.; Remuzzi, G.; Mendis, S.; Tonelli, M. The contribution of chronic kidney disease to the global burden of major noncommunicable diseases. Kidney Int. 2011, 80, 1258-1270. [CrossRef] [PubMed]

3. Kidney Care UK. Facts and Stats. Available online: https://www.kidneycareuk.org/news-and-campaigns/ facts-and-stats/ (accessed on 7 March 2019).

4. Kerr, M. Chronic Kidney Disease in England: The Human and Financial Cost; Insight Health Economics Ltd.: Twickenham, UK, 2012; p. 10.

5. Lewis, R. Understanding Chronic Kidney Disease: A Guide for the Non-Specialist; M\&K Update Ltd.: Keswick, UK, 2011.

6. Foreman, K.J.; Marquez, N.; Dolgert, A.; Fukutaki, K.; Fullman, N.; McGaughey, M.; Pletcher, M.A.; Smith, A.E.; Tang, K.; Yuan, C.W.; et al. Forecasting life expectancy, years of life lost, and all-cause and cause-specific mortality for 250 causes of death: Reference and alternative scenarios for 2016-40 for 195 countries and territories. Lancet 2018, 392, 2052-2090. [CrossRef]

7. Dialysis-NHS. Available online: https://www.nhs.uk/conditions/dialysis/ (accessed on 7 March 2019).

8. Miller, D.L.; O'Grady, N.P. Guidelines for the Prevention of Intravascular Catheter-related Infections: Recommendations Relevant to Interventional Radiology for Venous Catheter Placement and Maintenance. J. Vasc. Interv. Radiol. 2012, 23, 997-1007. [CrossRef] [PubMed]

9. Kramer, R.D.; Rogers, M.A.M.; Conte, M.; Mann, J.; Saint, S.; Chopra, V. Are antimicrobial peripherally inserted central catheters associated with reduction in central line-associated bloodstream infection? A systematic review and meta-analysis. AJIC Am. J. Infect. Control 2017, 45, 108-114. [CrossRef] [PubMed]

10. Mendu, M.L.; May, M.F.; Kaze, A.D.; Graham, D.A.; Cui, S.; Chen, M.E.; Shin, N.; Aizer, A.A.; Waikar, S.S. Non-Tunneled versus tunneled dialysis catheters for acute kidney injury requiring renal replacement therapy: A prospective cohort study. BMC Nephrol. 2017, 18, 1-7. [CrossRef]

11. van Oevelen, M.; Abrahams, A.C.; Weijmer, M.C.; Nagtegaal, T.; Dekker, F.W.; Rotmans, J.I.; Meijvis, S.C.A.; Bijlsma, J.A.; van der Bogt, K.E.A.; van de Brug, A.; et al. Precurved non-tunnelled catheters for haemodialysis are comparable in terms of infections and malfunction as compared to tunnelled catheters: A retrospective cohort study. J. Vasc. Access 2019, 20, 307-312. [CrossRef] [PubMed]

12. Sutherland, D.W.; Zhang, X.; Charest, J.L. Water infused surface protection as an active mechanism for fibrin sheath prevention in central venous catheters. Artif. Organs 2017, 41, E155-E165. [CrossRef]

13. Ripa, M.; Morata, L.; Rodríguez-Núñez, O.; Cardozo, C.; Puerta-Alcalde, P.; Hernández-Meneses, M.; Ambrosioni, J.; Linares, L.; Bodro, M.; Valcárcel, A.; et al. Short-term peripheral venous catheter-related bloodstream infections: Evidence for increasing prevalence of gram-negative microorganisms from a 25-year prospective observational study. Antimicrob. Agents Chemother. 2018, 62, e00892-18. [CrossRef]

14. Miller, L.M.; Clark, E.; Dipchand, C.; Hiremath, S.; Kappel, J.; Kiaii, M.; Lok, C.; Luscombe, R.; Moist, L. Hemodialysis tunneled catheter noninfectious complications. Can. J. Kidney Health Dis. 2016, 3, 2054358116669130. [CrossRef]

15. Wiese, L.; Mejer, N.; Schønheyder, H.C.; Westh, H. A nationwide study of comorbidity and risk of reinfection after Staphylococcus aureus bacteraemia. J. Infect. 2013, 67, 199-205. [CrossRef] 
16. Brass, P.; Hellmich, M.; Kolodziej, L.; Schick, G.; Af, S. Ultrasound guidance versus anatomical landmarks for internal jugular vein catheterization. Cochrane Database Syst. Rev. 2015. [CrossRef] [PubMed]

17. Wang, H.; Tong, H.; Liu, H.; Wang, Y.; Wang, R.; Gao, H.; Yu, P.; Lv, Y.; Chen, S.; Wang, G.; et al. Effectiveness of antimicrobial-coated central venous catheters for preventing catheter-related blood-stream infections with the implementation of bundles: A systematic review and network meta-analysis. Ann. Intensive Care 2018, 8, 71. [CrossRef] [PubMed]

18. Zanini, S.; Polissi, A.; Maccagni, E.A.; Dell'Orto, E.C.; Liberatore, C.; Riccardi, C. Development of antibacterial quaternary ammonium silane coatings on polyurethane catheters. J. Colloid Interface Sci. 2015, 451, 78-84. [CrossRef] [PubMed]

19. Schneider, A.; Baldwin, I.; Souweine, B. What's new: Prevention of acute dialysis catheter-related infection. Intensive Care Med. 2018, 44, 356-358. [CrossRef] [PubMed]

20. Keum, H.; Kim, J.Y.; Yu, B.; Yu, S.J.; Kim, J.; Jeon, H.; Lee, D.Y.; Im, S.G.; Jon, S. Prevention of bacterial colonization on catheters by a one-step coating process involving an antibiofouling polymer in water. ACS Appl. Mater. Interfaces 2017, 9, 19736-19745. [CrossRef]

21. Lok, C.E.; Mokrzycki, M.H. Prevention and management of catheter-related infection in hemodialysis patients. Kidney Int. 2011, 79, 587-598. [CrossRef]

22. Mogi, N.; Nakagawa, M.; Matsumae, H.; Hattori, A.; Shimohira, M.; Shibamoto, Y. Fibrin sheath of a peripherally inserted central catheter undepicted with gray-scale (real-time B-mode) ultrasonography: A case report. Radiol. Case Rep. 2018, 13, 537-541. [CrossRef] [PubMed]

23. Valliant, A.M.; Chaudhry, M.K.; Yevzlin, A.; Astor, B.; Chan, M.R. Tunneled dialysis catheter exchange with fibrin sheath disruption is not associated with increased rate of bacteremia. J. Vasc. Access 2015, 16, 52-56. [CrossRef]

24. Wang, L.H.; Wei, F.; Jia, L.; Lu, Z.; Wang, B.; Dong, H.Y.; Yu, H.B.; Sun, G.J.; Yang, J.; Li, B.; et al. Fibrin sheath formation and intimal thickening after catheter placement in dog model: Role of hemodynamic wall shear stress. J. Vasc. Access 2015, 16, 275-284. [CrossRef]

25. Ahmed, R.; Chapman, S.A.; Tantrige, P.; Hussain, A.; Johnston, E.W.; Fang, C.; Ammar, T.; Huang, D.Y.; Wilkins, C.J.; Garzillo, G.; et al. TuLIP (Tunnelled Line Intraluminal Plasty): An alternative technique for salvaging haemodialysis catheter patency in fibrin sheath formation. Cardiovasc. Interv. Radiol. 2019, 42, 770-774. [CrossRef]

26. May, R.M.; Brennan, A.B.; Fraser, J.C.; Drinker, M.C.; Mann, E.E.; Reddy, S.T.; Magin, C.M.; Siedlecki, C.A. An engineered micropattern to reduce bacterial colonization, platelet adhesion and fibrin sheath formation for improved biocompatibility of central venous catheters. Clin. Transl. Med. 2015, 4, 1-8. [CrossRef]

27. UV-CURE SILICONES ENABLE NEW MEDICAL DEVICE DESIGN CONCEPTS AND INCREASE CUSTOMER VALUE. Available online: https://www.freudenbergmedical.com/ecomaXL/files/UV-Cure_ Silicones.pdf?download=1 (accessed on 14 August 2019).

28. Weisenberg, S.H.; Termaath, S.C.; Seaver, C.E.; Killeffer, J.A. Ventricular catheter development: Past, present, and future. J. Neurosurg. 2016, 125, 1504-1512. [CrossRef]

29. Yang, S.; Lee, Y.J.; Lin, F.; Yang, J.; Chen, K. Chitosan/Poly (vinyl alcohol) blending hydrogel coating improves the surface characteristics of segmented polyurethane urethral catheters. J. Biomed. Mater. Res. Part B 2007, 83, 304-313. [CrossRef]

30. Weisman, J.A.; Ballard, D.H.; Jammalamadaka, U.; Tappa, K.; Sumerel, J.; D'Agostino, H.B.; Mills, D.K.; Woodard, P.K. 3D printed antibiotic and chemotherapeutic eluting catheters for potential use in interventional radiology: In vitro proof of concept study. Acad. Radiol. 2019, 26, 270-274. [CrossRef]

31. Balne, P.K.; Harini, S.; Dhand, C.; Dwivedi, N.; Chalasani, M.L.S.; Verma, N.K.; Barathi, V.A.; Beuerman, R.; Agrawal, R.; Lakshminarayanan, R. Surface characteristics and antimicrobial properties of modified catheter surfaces by polypyrogallol and metal ions. Mater. Sci. Eng. C 2018, 90, 673-684. [CrossRef]

32. Falk, A. The Role of Surface Coatings on Central Venous and Hemodialysis Catheters. Endovasc. Today 2008, 28-30.

33. Ps, S.; Shah, N. Heparin-bonded catheters for prolonging the patency of central venous catheters in children. Cochrane Database Syst. Rev. 2014, 3-5. [CrossRef]

34. Nicolas, D.R.M. Heparin Induced Thrombocytopenia (HIT); StatPearls: Treasure Island, FL, USA, 2018.

35. Kasirajan, K. Outcomes after heparin-Induced thrombocytopenia in patients with propaten vascular grafts. Ann. Vasc. Surg. 2012, 26, 802-808. [CrossRef] 
36. Franci, G.; Falanga, A.; Galdiero, S.; Palomba, L.; Rai, M.; Morelli, G.; Galdiero, M. Silver nanoparticles as potential antibacterial agents. Molecules 2015, 20, 8856-8874. [CrossRef]

37. Reidy, B.; Haase, A.; Luch, A.; Dawson, A.K.; Lynch, I. Mechanisms of silver nanoparticle release, transformation and toxicity: A critical review of current knowledge and recommendations for future studies and applications. Materials 2013, 6, 2295-2350. [CrossRef]

38. Wu, K.; Yang, Y.; Zhang, Y.; Deng, J.; Lin, C. A ntimicrobial activity and cytocompatibility of silver nanoparticles coated catheters via a biomimetic surface functionalization strategy. Int. J. Nanomed. 2015, 10, 7241-7252. [CrossRef]

39. Kuehl, R.; Brunetto, P.S.; Woischnig, A.K.; Varisco, M.; Rajacic, Z.; Vosbeck, J.; Terracciano, L.; Fromm, K.M.; Khanna, N. Preventing implant-associated infections by silver coating. Antimicrob. Agents Chemother. 2016, 60, 2467-2475. [CrossRef]

40. Freitas, P.D. Incorporation of Silver Nanoparticles by the Irradiation Process in Central Venous Catheter (CVC) of Polyurethane Coated with Titanium Oxide for Antimicrobial Activity. Master's Thesis, Instituto de Pesquisas Energéticas e Nucleares, Sao Paulo, Brazil, July 2018.

41. Chen, Y.M.; Dai, A.P.; Shi, Y.; Liu, Z.J.; Gong, M.F.; Yin, X.B. Effectiveness of silver-impregnated central. venous catheters for preventing catheter-related blood stream infections: A meta-analysis. Int. J. Infect. Dis. 2014, 29, e279-e286. [CrossRef]

42. Iqtedar, M.; Aslam, M.; Akhyar, M.; Shehzaad, A.; Abdullah, R.; Kaleem, A. Extracellular biosynthesis, characterization, optimization of silver nanoparticles (AgNPs) using Bacillus mojavensis BTCB15 and its antimicrobial activity against multidrug resistant pathogens. Prep. Biochem. Biotechnol. 2019, 49, 136-142. [CrossRef]

43. Roe, D.; Karandikar, B.; Bonn-Savage, N.; Gibbins, B.; Roullet, J. baptiste Antimicrobial surface functionalization of plastic catheters by silver nanoparticles. J. Antimicrob. Chemother. 2008, 61, 869-876. [CrossRef]

44. Kubo, A.L.; Capjak, I.; Vrček, I.V.; Bondarenko, O.M.; Kurvet, I.; Vija, H.; Ivask, A.; Kasemets, K.; Kahru, A. Antimicrobial potency of differently coated 10 and $50 \mathrm{~nm}$ silver nanoparticles against clinically relevant bacteria Escherichia coli and Staphylococcus aureus. Colloids Surf. B Biointerfaces 2018, 170, 401-410. [CrossRef]

45. Kim, S.H.; Lee, H.S.; Ryu, D.S.; Choi, S.J.; Lee, D.S. Antibacterial activity of silver-nanoparticles against Staphylococcus aureus and Escherichia coli. Korean J. Microbiol. Biotechnol. 2011, 39, 77-85.

46. Chopra, I. The increasing use of silver-based products as antimicrobial agents: A useful development or a cause for concern? J. Antimicrob. Chemother. 2007, 59, 587-590. [CrossRef]

47. Percival, S.L.; Bowler, P.G.; Russell, D. Bacterial resistance to silver in wound care. J. Hosp. Infect. 2005, 60, 1-7. [CrossRef]

48. Silver, S. Bacterial silver resistance: Molecular biology and uses and misuses of silver compounds. FEMS Microbiol. Rev. 2003, 27, 341-353. [CrossRef]

49. Korani, M.; Ghazizadeh, E.; Korani, S.; Hami, Z.; Mohammadi-Bardbori, A. Effects of silver nanoparticles on human health. Eur. J. Nanomed. 2015, 7, 51-62. [CrossRef]

50. Stenger, M.; Klein, K.; Grønnemose, R.B.; Klitgaard, J.K.; Kolmos, H.J.; Lindholt, J.S.; Alm, M.; Thomsen, P.; Andersen, T.E. Co-release of dicloxacillin and thioridazine from catheter material containing an interpenetrating polymer network for inhibiting device-associated Staphylococcus aureus infection. J. Control. Release 2016, 241, 125-134. [CrossRef]

51. Zanwar, S.; Jain, P.; Gokarn, A.; Kumar, S.; Punatar, S.; Khurana, S.; Bonda, A.; Pruthy, R.; Bhat, V.; Qureshi, S.; et al. Antibiotic lock therapy for salvage of tunneled central venous catheters with catheter colonization and catheter-related bloodstream infection. Transpl. Infect. Dis. 2019, 21, e13017. [CrossRef]

52. Melocchi, A.; Parietti, F.; Maroni, A.; Foppoli, A.; Gazzaniga, A.; Zema, L. Hot-melt extruded filaments based on pharmaceutical grade polymers for 3D printing by fused deposition modeling. Int. J. Pharm. 2016, 509, 255-263. [CrossRef]

53. Weisman, J.A.; Nicholson, J.C.; Tappa, K.; Jammalamadaka, U.; Wilson, C.G.; Mills, D.K. Antibiotic and chemotherapeutic enhanced three-dimensional printer filaments and constructs for biomedical applications. Int. J. Nanomed. 2015, 10, 357-370. [CrossRef]

54. Sousa, C.; Teixeira, P.; Oliveira, R. Influence of surface properties on the adhesion of staphylococcus epidermidis to acrylic and silicone. Int. J. Biomater. 2009, 2009, 1-9. [CrossRef] 
55. Lalehpour, A.; Janeteas, C.; Barari, A. Surface roughness of FDM parts after post-processing with acetone vapor bath smoothing process. Int. J. Adv. Manuf. Technol. 2018, 95, 1505-1520. [CrossRef]

56. Pérez, M.; Medina-Sánchez, G.; García-Collado, A.; Gupta, M.; Carou, D. Surface quality enhancement of fused deposition modeling (FDM) printed samples based on the selection of critical printing parameters. Materials 2018, 11, 1382. [CrossRef]

57. Keating, A.V.; Soto, J.; Tuleu, C.; Forbes, C.; Zhao, M.; Craig, D.Q.M. Solid state characterisation and taste masking efficiency evaluation of polymer based extrudates of isoniazid for paediatric administration. Int. J. Pharm. 2018, 536, 536-546. [CrossRef]

58. Verstraete, G.; Van Renterghem, J.; Van Bockstal, P.-J.; Kasmi, S.; De Geest, B.; De Beer, T.; Remon, J.P.; Vervaet, C. Hydrophilic thermoplastic polyurethanes for the manufacturing of highly dosed oral sustained release matrices via hot melt extrusion and injection molding. Int. J. Pharm. 2016, 506, 214-221. [CrossRef]

59. Muwaffak, Z.; Goyanes, A.; Clark, V.; Basit, A.W.; Hilton, S.T.; Gaisford, S. Patient-specific 3D scanned and 3D printed antimicrobial polycaprolactone wound dressings. Int. J. Pharm. 2017, 527, 161-170. [CrossRef]

60. Tan, D.K.; Maniruzzaman, M.; Nokhodchi, A. Advanced pharmaceutical applications of hot-melt extrusion coupled with fused deposition modelling (FDM) 3D printing for personalised drug delivery. Pharmaceutics 2018, 10, 203. [CrossRef]

61. Alhijjaj, M.; Belton, P.; Qi, S. An investigation into the use of polymer blends to improve the printability of and regulate drug release from pharmaceutical solid dispersions prepared via fused deposition modeling (FDM) 3D printing. Eur. J. Pharm. Biopharm. 2016, 108, 111-125. [CrossRef]

62. Tappa, K.; Jammalamadaka, U. Novel biomaterials used in medical 3D printing techniques. J. Funct. Biomater. 2018, 9, 17. [CrossRef]

63. Stewart, A.S.; Domínguez-Robles, J.; Donnelly, F.R.; Larrañeta, E. Implantable polymeric drug delivery devices: Classification, manufacture, materials, and clinical applications. Polymers 2018, 10, 1379. [CrossRef]

64. Domínguez-Robles, J.; Martin, K.N.; Fong, L.M.; Stewart, A.S.; Irwin, J.N.; Rial-Hermida, I.M.; Donnelly, F.R.; Larrañeta, E. Antioxidant PLA composites containing lignin for 3d printing applications: A potential material for healthcare applications. Pharmaceutics 2019, 11, 165. [CrossRef]

65. Pawar, R.P.; Tekale, S.U.; Shisodia, S.U.; Totre, J.T.; Domb, A.J. Biomedical applications of Poly (Lactic Acid). Rec. Pat. Regen. Med. 2014, 4, 40-51. [CrossRef]

66. Jacobi, C.; Friedrich, T.; Lüdtke-Buzug, K. Synthesis and characterisation of superparamagnetic polylactic acid based polymers. Int. J. Magn. Part. Imaging 2017, 3, 1710001.

67. Masutani, K.; Kimura, Y. PLA Synthesis and Polymerization. In Poly(Lactic Acid) Science and Technology: Processing, Properties, Additives and Applications; Jiménez, A., Peltzer, M., Ruseckaite, R., Eds.; Royal Society of Chemistry: London, UK, 2014; ISBN 9781782624806.

68. Farah, S.; Anderson, D.G.; Langer, R. Physical and mechanical properties of PLA, and their functions in widespread applications-A comprehensive review. Adv. Drug Deliv. Rev. 2016, 107, 367-392. [CrossRef]

69. Romanov, V.; Samuel, R.; Chaharlang, M.; Jafek, A.R.; Frost, A.; Gale, B.K. FDM 3D printing of high-pressure, heat-resistant, transparent microfluidic devices. Anal. Chem. 2018, 90, 10450-10456. [CrossRef]

70. Guerra, A.J.; Cano, P.; Rabionet, M.; Puig, T.; Ciurana, J. 3D-printed PCL/PLA composite stents: Towards a new solution to cardiovascular problems. Materials 2018, 11, 1679. [CrossRef]

71. Li, D.; Guo, G.; Fan, R.; Liang, J.; Deng, X.; Luo, F.; Qian, Z. PLA/F68/Dexamethasone implants prepared by hot-melt extrusion for controlled release of anti-inflammatory drug to implantable medical devices: I. Preparation, characterization and hydrolytic degradation study. Int. J. Pharm. 2013, 441, 365-372. [CrossRef]

72. Li, D.; Guo, G.; Deng, X.; Fan, R.; Guo, Q.; Fan, M.; Liang, J.; Luo, F.; Qian, Z. PLA/PEG-PPG-PEG/Dexamethasone implant prepared by hot-melt extrusion for controlled release of immunosuppressive drug to implantable medical devices, part 2: In vivo evaluation. Drug Deliv. 2013, 20 , 134-142. [CrossRef]

73. Visscher, L.E.; Dang, H.P.; Knackstedt, M.A.; Hutmacher, D.W.; Tran, P.A. 3D printed Polycaprolactone scaffolds with dual macro-microporosity for applications in local delivery of antibiotics. Mater. Sci. Eng. C 2018, 87, 78-89. [CrossRef]

74. Fu, J.; Yu, X.; Jin, Y. 3D printing of vaginal rings with personalized shapes for controlled release of progesterone. Int. J. Pharm. 2018, 539, 75-82. [CrossRef] 
75. Johansson, K.; Greis, G.; Johansson, B.; Grundtmann, A.; Pahlby, Y.; Törn, S.; Axelberg, H.; Carlsson, P. Evaluation of a new PVC-free catheter material for intermittent catheterization: A prospective, randomized, crossover study. Scand. J. Urol. 2013, 47, 33-37. [CrossRef]

76. Sharma, R.; Singh, R.; Penna, R.; Fraternali, F. Investigations for mechanical properties of Hap, PVC and PP based 3D porous structures obtained through biocompatible FDM filaments. Compos. Part B Eng. 2018, 132, 237-243. [CrossRef]

77. Rusu, M.; Ursu, M.; Rusu, D. Poly(vinyl chloride) and poly(e-caprolactone) blends for medical use. J. Thermoplast. Compos. Mater. 2006, 19, 173-190. [CrossRef]

78. Simons, F.J.; Wagner, K.G. Modeling, design and manufacture of innovative floating gastroretentive drug delivery systems based on hot-melt extruded tubes. Eur. J. Pharm. Biopharm. 2019, 137, 196-208. [CrossRef]

79. Haryńska, A.; Gubanska, I.; Kucinska-Lipka, J.; Janik, H. Fabrication and characterization of flexible medical-grade tpu filament for fused deposition modeling 3dp technology. Polymers 2018, 10, 1304. [CrossRef]

80. Gupta, S.; Ramamurthy, P.C.; Madras, G. Synthesis and characterization of silicone polymer/functionalized mesostructured silica composites. Polym. Chem. 2011, 2, 2643-2650. [CrossRef]

81. Thermal Analysis of Silicone Rubber. Available online: https://www.hitachi-hightech.com/file/global/pdf/ products/science/appli/ana/thermal/application_TA_018e.pdf (accessed on 14 August 2018).

82. Plott, J.; Shih, A. The extrusion-based additive manufacturing of moisture-cured silicone elastomer with minimal void for pneumatic actuators. Addit. Manuf. 2017, 17, 1-14. [CrossRef]

83. Hamidi, A.; Jain, S.; Tadesse, Y. 3D printing PLA and silicone elastomer structures with sugar solution support material. In Proceedings of the SPIE, Portland, OR, USA, 17 April 2017; Volume 10163.

84. Feneley, R.C.L.; Hopley, I.B.; Wells, P.N.T. Urinary catheters: History, current status, adverse events and research agenda. J. Med. Eng. Technol. 2015, 39, 459-470. [CrossRef]

85. Khatri, P.; Shah, M.K.; Vora, N. Formulation strategies for solid oral dosage form using 3D printing technology: A mini-review. J. Drug Deliv. Sci. Technol. 2018, 46, 148-155. [CrossRef]

86. Adamo, J.E.; Grayson, W.L.; Hatcher, H.; Swanton, J.; Thomas, A.; Hollister, S.; Steele, S.J. Regulatory interfaces surrounding the growing field of additive manufacturing of medical devices and biologic products. J. Clin. Transl. Sci. 2018, 2, 301-304. [CrossRef]

87. U.S. Food and Drug Administration. Technical Considerations for Additive Manufactured Medical Devices. Guidance for Industry and Food and Drug Administration Staff; U.S. Food and Drug Administration: Silver Spring, MD, USA, 2017.

(C) 2019 by the authors. Licensee MDPI, Basel, Switzerland. This article is an open access article distributed under the terms and conditions of the Creative Commons Attribution (CC BY) license (http://creativecommons.org/licenses/by/4.0/). 